\title{
Clipboard
}

\section{Rats are nicer than we think, at least to each other}

It comes as a shock to my non-biologist friends when I tell them that a major puzzle that preoccupies evolutionary biologists is the existence of niceness, good behaviour, cooperation and altruism in animals and humans. Should you rather not be concerned about the widespread selfishness, competition and backstabbing, they ask. The problem is that we are much concerned with what we cannot explain and find little interest in what is easily explained. In his theory of natural selection, which indeed has competitive selfishness as its cornerstone, Charles Darwin provided in one stroke, a logical thread that binds together an unprecedented number of biological facts. Cooperation and altruism were however the few exceptions that appeared to slip out of the thread of Darwinian logic. The challenge that evolutionary biologists have set for themselves is to see if cooperation and altruism too can be accomodated within Darwinian logic.

JBS Haldane was the first to show how Darwin's logic can be modified to accommodate altruism. Haldane shifted our focus from the individual animal that performs an act of altruism to the genes that affect behaviour and cause it to behave altruistically. He argued that genes that cause their bearers to be selectively altruistic toward other bearers of copies of the same gene, might indeed increase their representation in the gene pool of the population. In addition to offspring, close genetic relatives would also carry copies of one's genes so that altruism directed at kin might not be so paradoxical after all. This is the germ of the idea that Hamilton developed into a mathematically precise formulation that has come to be known variously as Inclusive Fitness Theory, Kin Selection or Hamilton's Rule. Hamilton's Rule has achieved a fair degree of success in demystifying many examples of cooperation and altruism in the animal, plant and microbial world (Gadagkar 1997). Unfortunately Hamilton's rule is inadequate when altruism is directed toward non-relatives and this is not really so uncommon.

Robert Trivers first tackled the remaining problem, that of altruism among non-relatives, by proposing the idea of Reciprocal Altruism - the idea that self-sacrificing altruism is not paradoxical if the altruist and the beneficiary exchange places and favours are returned promptly (Trivers 1971). This sounds like a good idea but it has been hard to document in animals. Cognitive abilities to recognise past helpers so as to selectively return favours and even more important, to remember, recognise and punish cheaters who take help and do not reciprocate, may be absent or limited in animals. Reciprocal altruism may work more effectively in humans but even here it cannot explain many acts of altruism directed at strangers without a history of specifically helping the altruist. Indirect reciprocity or the idea that A helps B because $\mathrm{B}$ is known to have helped C, may be somewhat easier to evolve but it still needs cognitive abilities and a knowledge of the behaviour of different individuals in the population (Nowak and Sigmund 1998; Leimar and Hammerstein 2001). A much more powerful idea is that of Generalized Reciprocity according to which individuals are more likely to help any one in need, after having received help from some one else. Such a mechanism does indeed seem to work in humans but there has hitherto been no evidence that animals can display generalized reciprocity. In a recent paper in the open access journal PloS Biology, Claudia Rutte and Michael Taborsky of the Department of Behavioural Ecology, University of Berne (Rutte and Taborsky 2007) report the results of an experiment which shows that female rats are more likely to help an unfamiliar rat if they had previously been helped by another unfamiliar rat.

Their experimental setup is simple. Pairs of rats are kept in a cage that has a mesh partition to keep the rats away from each other. One of them can pull a stick that is fixed to a baited tray and by doing so can produce an oat flake for the other rat but none for herself. The main result of the experiment is that rats that had previously received help by another rat pulling the stick and providing them with an oat flake, showed a $21 \%$ higher frequency of similarly helping an anonymous rat, compared to rats that had not been previously so helped. Helped rats also pulled the stick and helped another rat four times sooner after an oat flake was made available for the purpose, compared to rats that had not received help previously.

Keywords. Altruism; cooperation; generalized reciprocity; rat behaviour 
Rutte and Taborsky interpret these results as proof of the ability of rats to show generalized reciprocity. I think this is both a fascinating and an important finding, fascinating because generalized reciprocity was not hitherto known among non-human animals and important because it adds significantly to our arsenal of tools to resolve the Darwinian paradox of cooperation and altruism in animals.

The experiment of Rutte and Taborsky appears simple and straightforward. Why then did not others do similar experiments before? Why was generalized reciprocity in animals not discovered sooner? There are many examples in biology where people have long desired to do a particular experiment but could not do it until a specific technological advance made it possible. Experiments in animal behaviour are seldom of this kind. Important experiments in animal behaviour are made possible, not usually by advances in technology but by advances in theory. Michael Taborsky has been at the forefront of the effort to tackle the paradox of cooperation and altruism. He has recently been involved in demonstrating through computer simulations, that generalized reciprocity can lead to the evolution of cooperation and was probably the first person to use the term generalized reciprocity (Pfeiffer et al 2005; Hamilton and Taborsky 2005). This theoretical engagement was probably necessary for him to think of this otherwise simple experiment.

I believe that there is at least one more reason why Taborsky might have thought of this experiment. Most of us, even those of us who work with animals, tend to instinctively believe that animals are incapable of human-like thoughts and emotions. Generalized reciprocity can be interpreted as something like a "feel-good factor" that makes the recipient of help be in a "mood" to help anyone. This very interpretation of the possible mechanism of generalized reciprocity makes many of us to count animals out. But we have no difficulty in imagining that humans can have mood swings that affect our behaviour. In a fascinating experiment with humans it was revealed that individuals who had unexpectedly found a coin in the telephone booth were more likely to assist a stranger with a simple task such as picking up papers that he might have dropped on the street (Isen 1987). Most of us would tend to accept this as reasonable human behaviour but we would usually not be so inclined to believe that animals can behave in the same manner; i.e., help animal A because it was helped by animal B. Such intuitive assessment of animals as being "inferior" to humans is often wrong and continues to prevent a better understanding of the limits of animal psychology. Rutte and Taborsky were least likely to have been influenced by any such "superiority complex". Along with Martin Brinkhof of the Department of Social and Preventive Medicine in the University of Berne, Rutte and Taborsky have been thinking deeply about another remarkable phenomenon called "winner and loser effects" (Rutte et al 2006). It turns out that in a variety of animal species, an individual is more likely to win a fight with an opponent if it has recently won a fight with any other opponent and more likely to lose a fight with an opponent if it has recently lost a fight with any other opponent. Winning a fight appears to generate in animals a "feel-good" or "feel-confident" factor after winning a fight and a "feel-bad" or "feel-diffident" factor after losing a fight. And such psychological factors are known to affect the behaviour of animals. Now, it is not such a big leap in credibility to imagine a "feel-good" factor that promotes cooperative behaviour if a "feel-good" factor can promote confidence during a fight. Being familiar with winner and loser effects in animals, Rutte and Taborsky may not retain the usual incredulity about the possibility of animals experiencing a feel-good factor that might influence their propensity to help a stranger.

There is also an important advantage of thinking about winner effects, as Rutte and Taborsky do, in the context of generalized reciprocity. It opens up the possibility of understanding the physiological mechanisms in the body that promote a "feel-good" factor, be it in the context of winning a fight or in helping someone. I see therefore a distinct possibility of rapid progress in unravelling the proximate physiological mechanisms that promote cooperation and altruism and also selfishness. Some progress has already been made with humans (Uvnäs-Moberg 1998; Rilling et al 2002) in this context but deciphering the hormonal and neuronal mechanisms involved in promoting helpful behaviour in animals will be a major advance indeed.

\section{References}

Gadagkar R 1997 Survival strategies: - Cooperation and conflict in animal societies (Cambridge, Massachusetts; Hyderabad, India: Harvard University Press and Universities Press)

Hamilton I M and Taborsky M 2005 Contingent movement and cooperation evolve under generalized reciprocity; Proc. R. Soc. London B 272 2259-2267 
Isen A M 1987 Positive affect, cognitive processes, and social behavior; Adv. Exp. Soc. Psychol. 20 203-253

Leimar O and Hammerstein P 2001 Evolution of cooperation through indirect reciprocity; Proc. R. Soc. London B $268745-753$

Nowak M A and Sigmund K 1998 Evolution of indirect reciprocity by image scoring; Nature (London) 393 573-577

Pfeiffer T, Rutte C, Killingback T, Taborsky M and Bonhoeffer S 2005 Evolution of cooperation through generalized reciprocity; Proc. R. Soc. London B 272 1115-1120

Rilling J K, Gutman D A, Zeh T R, Pagnoni G, Berns G S and Kilts C D 2002 A Neural Basis for Social Cooperation; Neuron 35 395-405

Rutte C and Taborsky M 2007 Generalized Reciprocity in Rats; PLOS Biol. 5 1-5

Rutte C, Taborsky M and Brinkhof M W G 2006 What sets the odds of winning and losing?; Trends Ecol. Evol. 21 $16-21$

Trivers R L 1971 The Evolution of Reciprocal Altruism; Q. Rev. Biol. 46 35-57

Uvnäs-Moberg K 1998 Oxytocin may mediate the benefits of positive social interaction and emotions; Psychoneuroendocrinology 23 819-835

RAGHAVENDRA GADAGKAR Centre for Ecological Sciences

and

Centre for Contemporary Studies, Indian Institute of Science, Bangalore 560 012, India

(Email:ragh@ces.iisc.ernet.in)

ePublication: 28 November 2007 